\title{
TECHNOLOGY PLATFORMS AS A TOOL FOR SOLVING COMPLEX INNOVATION PROBLEMS
}

\author{
L.D. GITELMAN, M.V. KOZHEVNIKOV \& D.G. SANDLER \\ Ural Federal University, Russia.
}

\begin{abstract}
The article analyses the experience of using the concept of technology platforms for solving innovation problems of a complex multidimensional nature that stem from a lack of information and knowledge. Two cases are described when platform tools are applicable. The first one has to do with creating breakthrough technologies in promising industries, mostly high-tech ones, as well as with forecasting and developing competencies that are required for the new technology agenda. Second, they are applicable when major multinational corporations build their market infrastructure that requires stable system connections within value chains. The authors showcase their experience of engineering specialised university technology platforms that focus on introducing flexible and up-to-date educational products based on the integration of science, education, innovation and close cooperation with businesses.

Keywords: cooperation, education, high-tech industries, innovation, technology platform, technology transfer, uncertainty.
\end{abstract}

\section{INTRODUCTION}

In many countries, the transition to a new economy following the information technology revolution, which is conventionally referred to as 'digitalisation', or Industry 4.0, is accompanied by the development of the forms and mechanisms of innovation. The experience of other countries (for example, the USA, Great Britain, Germany, France) shows that it is impossible to create smart manufacturing systems and products without re-engineering intercorporate science and technology cooperation among the parties involved in the process of innovation: high-tech companies, infrastructure companies, universities, research centres, and service solutions suppliers [1].

Technology platforms (TP) often serve as a structural tool for such cooperation. They are usually built in new knowledge-based industries (biomedicine, smart energy, nuclear industry, urban infrastructure, robotics etc. See Fig. 1). The prospects of applying this tool to address poorly structured innovation problems are of significant scientific interest from the point of view of organisation and methodology in the first place. The analysis done by the authors enabled them to identify a number of conditions that ensure the viability of the platforms, and to come up with a project of a technology platform aimed at furthering anticipatory learning for the new industrial revolution.

\section{METHODOLOGICAL ASPECTS OF DESIGNING TECHNOLOGY PLATFORMS}

The consolidation of the best practices of operating technology platforms makes it possible to single out two main approaches to building them.

Under the first approach, a technology platform is a consortium (a global or a regional one) that is created to solve super complex problems, typically in the field of science and technology, on the basis of a single ideology and research methodology. The problems that are addressed on such 


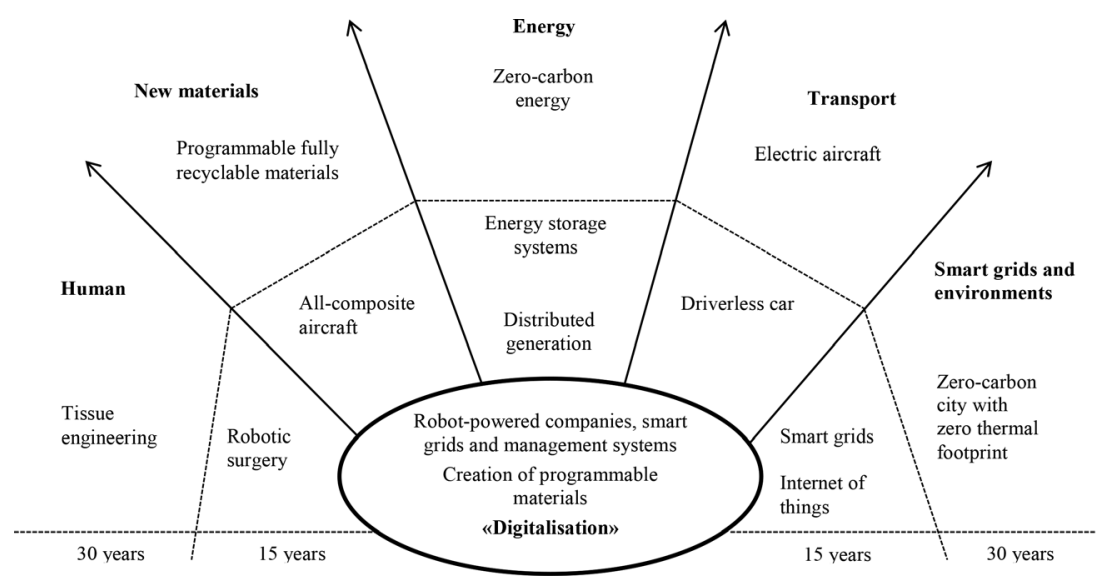

Figure 1: Examples of new industries and areas where the density of innovative businesses is growing (according to Technospark.ru).

platforms are always unique and one-of-a-kind. What makes them peculiar is their novelty, a nonlinear structure, a lack of knowledge, first and foremost of interdisciplinary kind, and almost complete absence of required analytics.

An example of such a problem is the development of smart grids that are sought after by companies from various industries related to the energy sector [2]. The scale of the problem, its organisational, technical, financial, economic and legal features require that energy companies establish cooperation and explore and expand the potential for cooperation with partners from various fields of business (Fig. 2). Appropriate technology platform can be called 'Intelligent Energy'.

The approach was common between 1990s and 2000s in Europe due to the need to boost innovative development and create an advanced technology market in the European Union. The first technology platform was built in 2001 for the purpose of organising and coordinating cooperation between aircraft manufacturers and scholarly communities in planning the programmes of aeronautics research. Today, there are some 40 technology platforms in Europe that conduct research to further the development of high-tech industries - machine building, energy, the space industry, telecommunications, bioeconomy, transport [3, 4].

The key prerequisite for building the European technology platforms was the need to reorganise the market of research intensive technologies. It was, therefore, the need to reduce R\&D costs in promising industries that spurred the creation of technology platforms in Europe. That was accomplished by drawing up a unified long-term innovation strategy of the territory that contained a package of appropriate legal and financial measures, by bundling companies that were working on identical products, by promoting cooperation among companies, universities and research centres.

The second approach is typical of the digital industry, although it does not contradict the first one, but complements and furthers it. A technology platform is understood as an 'innovation ecosystem' that is built around a 'keystone company' such as Google, Apple, or Facebook. A major firm acts as a provider of technologies of the future, with numerous smaller contractors, research centres, technology and logistics services, and, most importantly, customers gravitating towards it. The main 'product' of the platform is new markets founded on a new technology architecture [5-7]. 


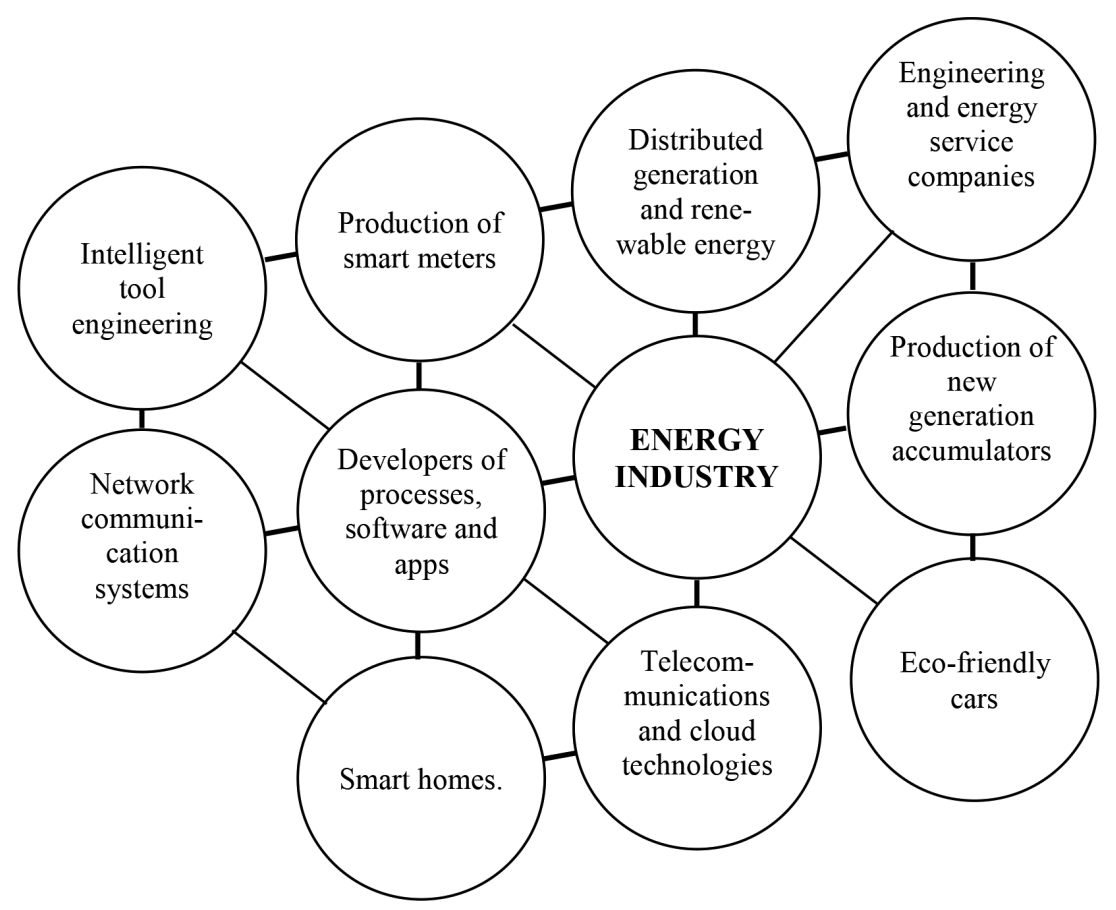

Figure 2: Platform and network structure of industry convergence in the course of building smart energy systems.

Technologies that are centrally developed by the keystone company are adapted to suit various groups of customers through the diffusion of innovations. As a result, the goal of the platform is to shape future preferences of a large group of potential customers. Such anticipatory impact ensures the keystone company's market stability for the next 5 to 10 years. The value of the technology platform grows as long as it attracts an ever increasing number of customers by generating a unique hybrid range of products to offer to them, and at the same time attracts new partners (entrepreneurs, developers, investors and other business entities) (Fig. 3).

One can, therefore, speak about the strategic importance of technology platforms for ensuring the competitive edge of individual research-intensive organisations as well as whole industries, regions and countries. It's no wonder that some scholars observe that competition among individual businesses will soon transform into competition among technology platforms [5, 8].

\section{COOPERATION BETWEEN UNIVERSITIES AND BUSINESS AS KEY DRIVER OF TP DEVELOPMENT}

The two approaches described above make it possible to define a technology platform as an alliance in which cooperation, especially on $\mathrm{R} \& \mathrm{D}$, plays a key role in the effectiveness and viability of the platform. Today, high-tech corporations tend to outsource to universities, research centres, think tanks and consulting agencies. This trend is described in a study by The Organisation for Economic Cooperation and Development (OECD) [9].

The ongoing changes in corporate R\&D models (from centralised R\&D functions to predominantly non-captive $R \& D$ projects) have brought about a significant transformation of the nature of 


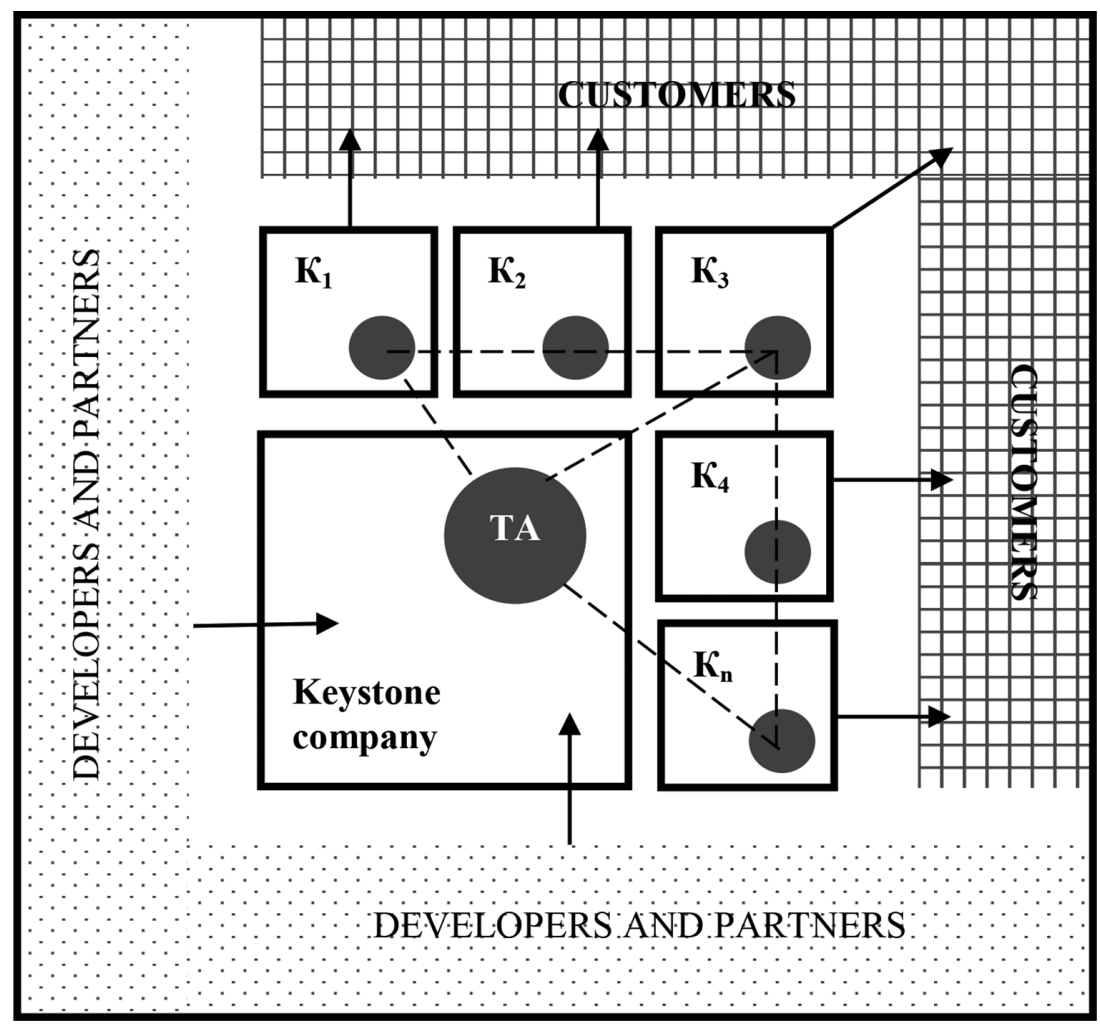

Figure 3: Visualisation of an 'innovation ecosystem'-type technology platform, $\mathrm{K}_{1} \ldots \mathrm{K}_{\mathrm{n}}$ are business structures of the keystone company that offer customers hybrid products built upon a single technology architecture (TA).

cooperation between university and business. Nowadays business seeks limited, but highly targeted partnerships with university structures. Such an attitude is due to two factors. First, the bulk of research being carried out in emerging industries is poorly structured and experiences an immense shortage of knowledge, which calls for cooperation with specialist research organisations, including universities. On the other hand, when a large number of external entities are involved in research, it gets harder to manage them; intellectual security risks intensify; problems arise with testing the market for innovations.

The empirical evidence from abroad [10-13] yields an observation that universities participating in technology platforms:

- act as developers and suppliers of new technologies for specific goals of business (so-called 'institutional agents');

- always take on the duty of designing an effective business model for commercialisation of the technologies;

- are actively engaged in handling the issues of intellectual property protection and patenting. For this purpose, they set up special university units ('transfer technology offices'). 


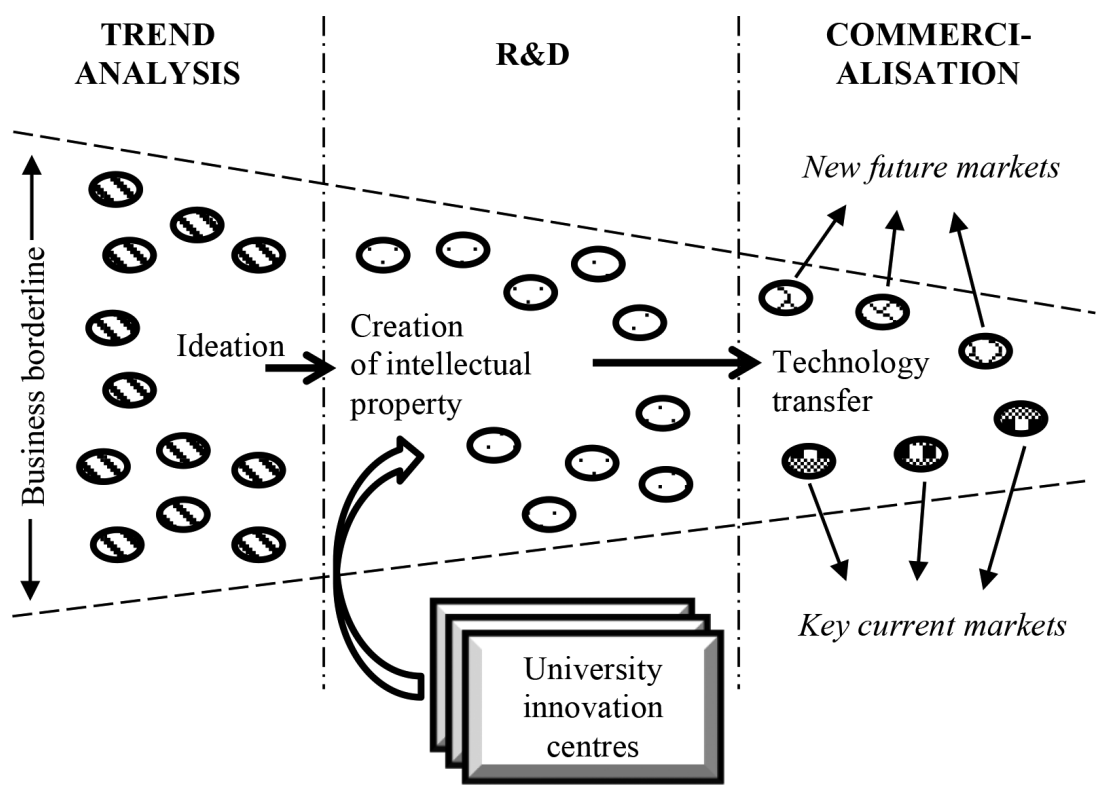

Figure 4: Place of university innovation centres in the chain of creating breakthrough innovation.

In most technology platforms, the participating university does not have much autonomy and rarely initiates the creation of a platform. One success story here is the case of the University Of Manchester (UK) that managed to bring together multinational enterprises from a range of industries (Astra-Zeneca, IBM, BP, Syngenta). The university proceeded from an idea that without cooperation with big businesses it could not continue to be a high-performing educational and research institution, to enhance the staff's competencies, to conduct a profound analysis of social, political, and economic trends, and finally, to improve its educational content [14].

The initiative, however, came from major agribusiness Syngenta AG that in 2007 made it a priority to expand cooperation with universities, and within a short period of time it established six so-called university innovation centres at research universities of Great Britain, China and Australia. The partnerships enabled the company to intensify efforts to create open innovations that are essentially aimed at shaping a long-term strategy of developing new technologies and markets for them (Fig. 4).

The involvement of universities in technology platforms opens opportunities for improving their core business - that of designing and implementing up-to-date interdisciplinary educational programmes using the latest achievements in science; creating new technologies for education, and promoting technological entrepreneurship. Generally speaking, a technology platform could form the foundation for a unique strategy of universities that implies convergence and integration of research, innovation and teaching for the purposes of anticipatory training of professionals.

\section{TECHNOLOGY PLATFORM FOR A BREAKTHROUGH IN PROFESSIONAL EDUCATION}

Super dynamic non-linear and all too often chaotic changes in the global environment and stronger competition, including in geopolitics, fuel the demand for a new model of managing business 
development. The core of the model is preventive actions of management, its ability to respond swiftly and adequately to new circumstances, and timely preparation for upcoming change.

Managers need new competencies:

- holistic vision of trends, processes and factors that determine the emergence, development and behaviour of complex systems in the global contest;

- decision making that takes into account interdisciplinary connections between technology, reliability and safety, economy and business results;

- quick adaptation to a situation that has changed at an early stage of its emergence;

- access to global knowledge bases, rapid analysis and generalisation of knowledge;

- organisation of an active innovation process at all levels of management.

This clearly calls for anticipatory learning that the authors define as the process of building competencies and knowledge for addressing future tasks that are in line with global trends and national development programmes.

A breakthrough is needed to introduce a new system, as soon as possible, that will make it possible to foresee scientific and research, social and economic and organisational innovations with specific stochastic characteristics, and to nurture competencies for rapid design of new educational products and quick readjustment of the learning process in order to be able to embrace promising industry technologies and tasks in a specific profession (Fig. 5).

$\begin{array}{cc}\text { UNIVERSITY: } & \text { BUSINESS: } \\ \text { science, education, innovation } & +\end{array}$

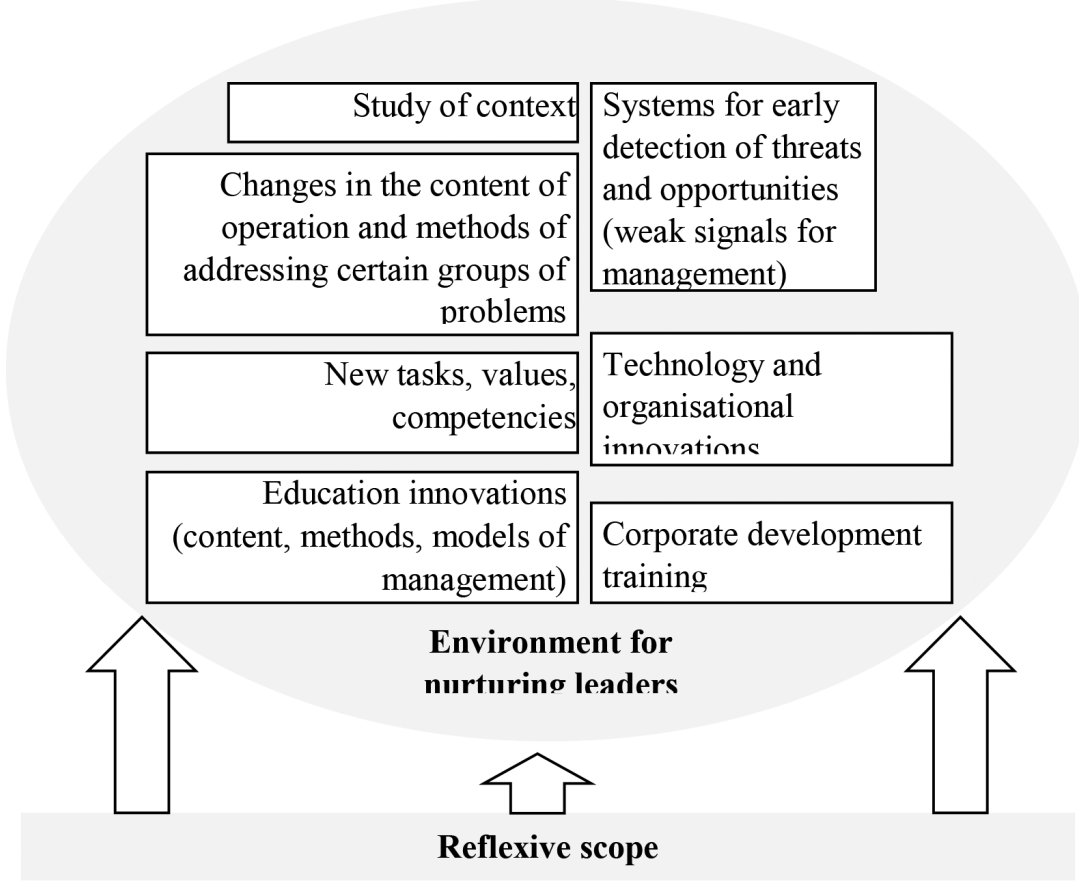

Figure 5: Conceptualisation of a breakthrough in anticipatory learning. 
The only way to solve the problem is by conducting purpose-specific studies that will focus on foreseeing technological development, shaping a vision of the future and integrating these activities with learning and innovation (both at university and in business).

What comes to the forefront is the specific mechanism of cooperation between science, education and business as part of a holistic system. This extremely complex system is unique because a real partnership will work if each unit of the 'science - education - business' trio have their interests and intellectual resources combined into a single project on the basis of a common focus, ambitions and methodological framework:

- pre-emptive solutions and anticipatory learning that supplies management with new knowledge and relevant competences:

- staff development using innovation and personal development tools;

- attention to achievements in science and technology and promising industrial technologies as a powerful and defining driver of contemporary economic development.

The authors' experience shows that the technology platform proves to be the most effective solution to the problem. Figure 6 depicts the structure of an anticipatory learning platform that is being introduced on the initiative of the research and education centre 'ENGEC' of Ural Federal University.

The Integrated System for Research, Consulting, Training and Transformation (ISCT) [15] provides a methodological framework for the platform. Among the technologies used within the ISCT methodology on the basis of its principles and approaches are 'Conveyor for nurturing new leaders', 'We engineer the future of our company (university) with our own hands', 'Making management

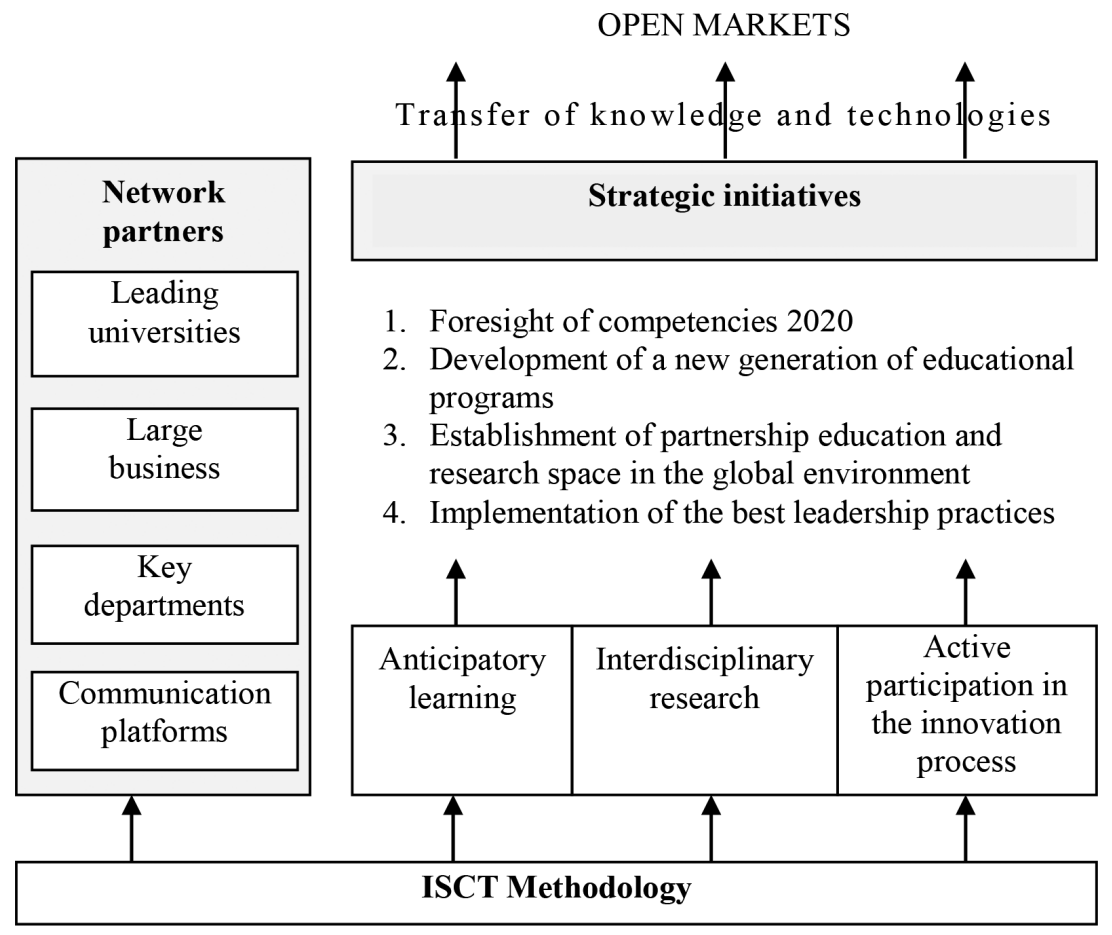

Figure 6: Structure of a technology platform for anticipatory learning. 
ready for modernisation and organisational transformation', 'Corporate management incubator', 'Corporate university academy', a series of organisational activity games, strategic and project sessions 'CLIMB to excellence'.

The methodology proposes a new framework of the vision of the holistic system described above. An intelligent 'super-smart' macro-environment is being created for governing the 'smart' environment' ('the smart above the smart').

The agenda of the priority research as part of the technology platform includes:

- interdisciplinary connections between technologies, environmental safety, investment, business results and the quality of human resources;

- principles of the engineering of the future and weak signal management systems;

- foresight methods;

- methods for the study of complex systems and risk assessment amid uncertainty;

- management of a corporate environment generating new knowledge and innovations;

- development of the principles and the structure of technology-based customised learning.

\section{CONCLUSION}

Present-day industrial challenges dictate the need to create technology platforms that focus on innovation, transformations and associated fields, including staff training. This stems from the emergence of new technologies and competencies that will be in demand soon. As a result, universities that bring together science, professional training and the introduction of innovation in emerging industries start to play a significant and peculiar role.

A good example is German universities as most of them combine platform clusters and focus on Industry 4.0 problems. Without close cooperation with major companies, universities are unable to work out a relevant research agenda. The results of studies are subsequently integrated into soughtafter educational content. This is how new courses or even branches of study appear, mechatronics, virtual prototyping, intelligent technical systems, and the internet of the things being some of the examples.

The authors' study shows that university technology platforms are an effective instrument for responding to the challenge. The platforms envisage the deployment of anticipatory learning solutions that are delivered in the global scientific and educational space that operates through networks involving leading universities, innovative businesses and various communication platforms.

\section{ACKNOWLEDGMENTS}

The work was supported by Act 211 of the Government of the Russian Federation, contract № 02.A03.21.0006.

\section{REFERENCES}

[1] Fatkhullin, B., Improving cross-company scientific, industrial and technological cooperation in the framework of technological platforms, [in Russian]. Transport Business in Russia, 6 , pp. 103-104, 2012.

[2] 'Smart' solutions for intelligent energy systems, [in Russian], available at https://www.pwc.ru/ en/energy-utilities-mining/publications/assets/smartgrid_rus.pdf

[3] Godenov, I.S., European Technology Platforms, [in Russian], Tomsk State University: Tomsk, p. $72,2011$. 
[4] Bebeshko, I.U., Technology platforms as a tool to promote innovative development of the Russian economy. Theory and Practice of Social Development, 12, pp. 506-508, 2009.

[5] Gawer, A., Bridging differing perspectives on technological platforms: Toward an integrative framework. Research Policy, 7(43), pp. 1239-1249, 2014.

[6] Osterwalder, A. \& Pigneur, Y., Business Model Generation, Wiley \& Sons: New Jersey, pp. 76-87, 2010.

[7] Shankar, V., Berry, L. \& Dotzel, T., A practical guide to combining products and services, available at https://hbr.org/2009/11/a-practical-guide-to-combining-products-and-services

[8] Malik, K., Georghiou, L. \& Grieve, B., Developing new technology platforms for new business models: Syngenta's partnership with the University of Manchester, available at https:// www.escholar.manchester.ac.uk/api/datastream?publicationPid=uk-ac-man-scw: 109173 \&datastreamId=POST-PEER-REVIEW-PUBLISHERS-DOCUMENT.PDF

[9] The Internationalisation of Business R\&D, Evidence, Impacts and Implications, OECD, 2008, available at www.sourceoecd.org/scienceIT/9789264044043

[10] Connecting Universities to Regional Growth: A Practical Guide, available at http://ec.europa. eu/regional_policy/sources/docgener/presenta/universities2011/universities2011_en.pdf

[11] Hammadou, H., Paty, S. \& Savona, M., Strategic interactions in public R\&D across European countries: a spatial econometric analysis. Research Policy, 7(43), pp. 1217-1226, 2014.

[12] Sendogdu, A. \& Diken, A., A research on the problems encountered in the collaboration between university and industry. Social and Behavioral Science, 99, pp. 966-975, 2013.

[13] Bubela, T. \& Caulfield, T., Role and reality: technology transfer at Canadian universities. Trends in Biotechnology, 9(28), pp. 447-451, 2010.

[14] Gitelman, L.D., Sandler, D.G., Kozhevnikov, M.V. \& Tretyakov, V.S., Technology platform as a tool for transformation of university science and education activities, [in Russian]. University Management: Practice and Analysis, 4(98), pp. 31-42, 2015.

[15] Gitelman, L.D., Isayev, A., Gavrilova, T., Gamburg, A., Gitelman, L.M., Yeliseyeva, K., Zorin, N., Kozhevnikov, M., Kostina, G., Rostik, O., Uglova, L., Chazov, A. \& Chazova, T., Methodology of Innovative Management Education, Ekonomika Publishing House: Moscow, pp. 53-65, 2015. 